\title{
Parental Warmth and Hostility and the Development of Psychopathic Behaviors: A Longitudinal Study of Young Offenders
}

\author{
Heidi Backman ${ }^{1,2} \cdot$ Taina Laajasalo $^{1} \cdot$ Markus Jokela $^{1} \cdot$ Eeva T. Aronen $^{2}$
}

Accepted: 3 February 2021 / Published online: 6 March 2021

(c) The Author(s) 2021

\begin{abstract}
Parental behaviors may shape levels of psychopathic traits and antisocial outcomes among youth. To better evaluate the potential causality of these associations, we used eight follow-ups from the Pathways to Desistance study of 1354 offending adolescents (14.3\% female; $40.1 \%$ black) and examined whether within-individual variation in parenting over time was associated with within-individual variation in psychopathic traits and offending. Multilevel regression models were adjusted for age, gender, ethnicity, contact with parental figure, and self-reported offending. Adolescent self-reported parental warmth was associated with lower psychopathic traits, and parental hostility with higher psychopathic traits. The results indicated that the more supportive and nurturing the parent, the lower the levels of psychopathic traits, whereas the more hostile the parent, the higher the levels, respectively. In addition, self-reported offending was predicted by higher parental hostility and lower maternal warmth. In time-lagged analysis, psychopathic traits did not predict parental behaviors. In young offenders parental warmth may protect against development of psychopathic traits in adolescence, whereas parental hostility may strengthen these traits. We conclude, that parenting quality matters in adolescence. Warm parenting style at this developmental period associates with lower psychopathic features among young offenders possibly lowering the risk of further criminal activity.
\end{abstract}

Keywords Psychopathy $\cdot$ Adolescent delinquency $\cdot$ Parental warmth $\cdot$ Parental hostility $\cdot$ Within-individual change

\section{Highlights}

- Maternal warmth was associated negatively with psychopathic traits and offending among adolescent delinquents.

- Paternal warmth protected from psychopathic traits but not from delinquency.

- Maternal and paternal hostility was linked positively to psychopathic traits and offending.

Psychopathy refers to a syndrome of personality pathology characterized by interpersonal, affective, and behavioral domains that include manipulation, lack of remorse or guilt, disregarding the feelings and rights of others, stimulation seeking, and impulsive and antisocial behaviors (Forth et al., 2003; Hare \& Neumann, 2008). It has a profound burden on

Heidi Backman

heidi.backman@helsinki.fi

1 Faculty of Medicine, Department of Psychology and Logopedics, University of Helsinki, Helsinki, Finland

2 Laboratory of Developmental Psychopathology, Child Psychiatry and Pediatric Research Center, Children's Hospital, University of Helsinki and Helsinki University Hospital, Helsinki, Finland public health, research and practice in correctional psychology, psychiatry and criminal justice systems (Reidy et al., 2015). Traits of callousness and unemotionality (CU) are suggested to be particularly important in the development of adult psychopathy, identifying a small subgroup of juveniles who later exhibit psychopathic traits as adults and show severe and stable patterns of antisocial lifestyles (Frick et al., 2014; Frick \& White, 2008). Despite the emphasis of CU traits in evaluating risks of psychopathy in adolescents, CU traits in combination with interpersonal and behavioral domains seem to designate a clinically interesting group with poorer adult life outcomes (Bergstrøm \& Farrington, 2018; Salekin et al., 2018). Adolescents with psychopathic traits show insensitivity to punishment and elevated reward-seeking behaviors (Byrd et al., 2014), and they are characterized by deficits in recognizing and 
responding to emotional expressions, especially distressed emotions (Dawel et al., 2012; Marsh \& Blair, 2008). The neurocognitive and socioemotional functional impairments of these youth resemble those discovered in adult psychopaths (Blair, 2013).

Psychopathic traits, especially CU behaviors, are often considered to be strongly influenced by early emerging, genetic predispositions (Frick \& White, 2008; Hyde et al., 2016). Studies of the etiology of psychopathy have particularly focused on temperamental, neurocognitive, and genetic factors (Blair, 2013; Frick et al., 2014; Viding \& McCrory, 2012), and the heritability of psychopathic traits is estimated to vary between $36 \%$ and $67 \%$ according to a meta-analysis (Moore et al., 2019; see also Viding \& McCrory, 2012). However, environmental factors may also contribute to the development and manifestation of psychopathy (Henry et al., 2018; Viding \& McCrory, 2012). Although psychopathic traits are thought to be relatively stable across childhood and adolescence (Frick et al., 2003; Frick et al., 2014; Lynam et al., 2009), neither the interpersonal, behavioral or affective domains are unchangeable during development (Lynam et al., 2008; Pardini et al., 2007; Waller et al., 2013; Wilkinson et al., 2016).

Understanding contextual preventive, protective and intervening factors for the development of psychopathy, along with risks, is important. Accumulating research shows that certain parenting factors may shape psychopathic-like behavior among children and adolescents (see Hawes et al., 2014; Waller et al., 2013 for reviews). Although harsh and coercive parenting has been linked to conduct problems more often among youth with low rather than high CU traits (Lynam et al., 2008; Pasalich et al., 2011; Viding et al., 2009), data also show associations between psychopathiclike traits emerging in early adolescence and childhood negative parenting (Barker et al., 2011; Pardini et al., 2007; Tuvblad et al., 2013). For example, one study found that low parental warmth in toddlerhood may increase $\mathrm{CU}$ behavior at age 10 to 12 and indirectly even at age 20 (Waller et al., 2015). Also, disrupted parental bonding, lack of maternal care, and parental harsh punishment in childhood may predict antisocial or psychopathic personalities in young adulthood (Gao et al., 2010; Goulter et al., 2020). The associations between negative parenting and CU traits in adolescence is much less studied than those between childhood parenting and later traits. Two cross-sectional studies using the same data set have found that those male adolescent offenders who reported lower levels of maternal warmth and involvement in teenage years scored higher on a measure of $\mathrm{CU}$ traits than those exposed to high levels of maternal care (Bisby et al., 2017; Kimonis et al., 2013).

Along with negative parenting and low parental warmth, positive parenting and high parental warmth have also been found to link to psychopathic-like behavior in early and late adolescence. For example, parental involvement and positive reinforcement associate with reduction in $\mathrm{CU}$ traits over time (Hawes et al., 2011; Pardini et al., 2007), and maternal sensitivity is considered to protect boys against psychopathic traits across toddlerhood to adolescence, especially when the sensitivity is continuous (Buck, 2015). Besides CU traits, parental warmth may also prevent antisocial behavior among young people with elevated $\mathrm{CU}$ traits (Pasalich et al., 2011; Ray et al., 2017). A recent study examined how $\mathrm{CU}$ traits assessed in the late childhood were retrospectively related to mother-child interaction styles at ages 5 to 7 (Goulter et al., 2020). Parental warmth was associated with a reduction in CU traits, which in turn were related to a reduction in antisocial symptoms in adulthood. Another longitudinal study of a community sample found that warm parenting at age 2 was associated with a slight reduction in CU traits at age 13 (Barker et al., 2011). In the Pathways to Desistance study among adolescents (Ray, 2018), parental warmth was one of the social factors associated with lower average CU traits, but when parental warmth was used as a time-varying covariate, there was no consistent associations with $\mathrm{CU}$ traits. Finally, a crosssectional study of juveniles ranging from 11 to 17 indicated that adolescent self-reported parental warmth was associated with fewer conduct problems for adolescents with low to medium levels of psychopathic traits, but not for adolescents with higher levels of psychopathic traits (Chinchilla \& Kosson, 2016).

In sum, studies have provided evidence that parental behavior may contribute to the manifestation of psychopathic traits; however, psychopathic traits in youth may also modify the environment, for example, by generating negative parenting which in turn increases psychopathic-like behavior (Flom et al., 2020; Larsson et al., 2008; Viding et al., 2012). Adolescent psychopathic traits may thus be more of a predictor of than a reaction to parental behavior (Muñoz et al., 2011; Salihovic et al., 2012). Notably, this kind of a reciprocal and supportive relationship between a parent and child may also promote the adoption of prosocial values and the development of guilt, empathy and conscience, which are associated with low levels of CU traits (Kochanska 1997; Frick \& White, 2008).

\section{Present Study}

Despite the demonstrated link between parental practices and psychopathic behavior (e.g., Ray, 2018), there is little research addressing the question of temporal direction and possible causality in the association between parenting and psychopathic traits in adolescence. One way to address this is to examine within-individual variations in parenting characteristics and psychopathic traits: if parental warmth is 
causally related to psychopathic traits, one would expect changes in parental warmth to become reflected in changes in psychopathic traits (cf. Jokela et al., 2018). Accordingly, we first hypothesized that parental warmth (i.e., a supportive and nurturing parental relationship) would be associated with lower psychopathic traits and less self-reported offending. Second, we hypothesized that parental hostility (i.e., parent's hostility, angry coerciveness, and antisocial behavior toward the adolescent) would be associated with higher psychopathic traits and more self-reported offending. Third, we hypothesized that the age of the participant would moderate the associations so that parental warmth and hostility would become less strongly associated with psychopathic traits with increasing age, as the adolescents gain more independence from their parents (Hill et al., 2007). Finally, we aimed to test the opposite direction of the effect and hypothesized that psychopathic traits would predict later parental warmth and hostility, because bidirectional effects between parental behavior and adolescent psychopathic traits have been proposed (Salihovic et al., 2012). In short, the questions for the study were: (1) does parental warmth and hostility predict changes in adolescent psychopathic traits and offending behavior, (2) do adolescent psychopathic traits predict changes in parental warmth and hostility, and (3) are the effects moderated by age?

The present study examines associations of parental warmth and hostility through adolescent self-report with self-reported adolescent's psychopathic traits in a high-risk sample of offending adolescents. The study takes into account the combination of affective, behavioral and interpersonal features of psychopathy as the overall construct might predict negative outcomes better than $\mathrm{CU}$ traits alone (Salekin et al., 2018). To better take into account confounding factors and possible bidirectional associations, we used longitudinal data with 8 assessments across 4.5 years of follow-up time with repeated measurements of adolescent self-reported parental relationship characteristics and psychopathic traits. This allowed us to examine whether changes in parental relationship characteristics were related to changes in psychopathic traits and self-reported offending within the same individuals followed over time (Curran \& Bauer, 2011), and whether parental relationship characteristics predict psychopathic traits, or vice versa.

\section{Method}

\section{Participants and Procedure}

The Pathways to Desistance study recruited offending youth who had been adjudicated delinquent or found guilty of a serious offense. Participants were 1354 adjudicated adolescents (1170 boys, 184 girls) between the ages of 14 and
17 years at the time of their offense. Two locations for data collection were selected: the metropolitan areas of Philadelphia and Phoenix, in the United States. The enrollment of the sample began in late 2000 and was completed in 2010. After the baseline interview, there were 10 follow-up interviews in total. These time-point interviews were computer-assisted and included a standard set of measures at 6- or 12-month intervals, beginning 6 months after the baseline interview and continuing for a 7-year follow-up period. The follow-up interviews assessed changes in different domains during the recall period of 6 or 12 months. The methods and procedures were approved by the participating universities' institutional review boards. A detailed description of the recruitment, the sample, and study methodologies are found elsewhere (Schubert et al., 2004).

Of the 10 follow-up interviews, the first eight over a 4.5-year period were included in the present study. As a result, the sample included 7135 person-observations of 1354 persons with a mean age of 17.6 years (standard deviation $(\mathrm{SD})=0.01)$. The age range was 14 to 19 years. The sample's ethnicity consisted of Black $(40.1 \%)$, Hispanic $(34.0 \%)$, White $(21.4 \%)$, and other $(4.4 \%)$. Due to different reasons (e.g., participant missed the interview, did not fill-in the measure, too few answers for computation, refusal), $24.7 \%$ of all potential person-observations were missing. Overall, the sample retention was high, approximately $90 \%$ of the full sample.

\section{Measures}

\section{Psychopathic traits}

The Youth Psychopathic Traits Inventory (YPI; Andershed et al., 2002) is a self-report measure with 50 items mapping onto 3 domains of psychopathy: affective (Callous-Unemotional), interpersonal (Grandiose-Manipulative), and behavioral (Impulsive-Irresponsible). The measure has 10 subscales, each containing 5 questions: dishonest charm (e.g., "I have the ability to con people by using my charm and smile"), grandiosity (e.g., "I'm better than everyone on almost everything"), lying (e.g., "Sometimes I lie for no reason, other than because it's fun"), manipulation (e.g., "I can make people believe almost anything"), remorselessness (e.g., "To feel guilt and regret when you have done something wrong is a waste of time"), unemotionality (e.g., "I usually feel calm when other people are scared"), callousness (e.g., "I think that crying is a sign of weakness, even if no one sees you"), thrill seeking (e.g., "I like to be where exciting things happen"), impulsiveness (e.g., "I consider myself as a pretty impulsive person"), and irresponsibility (e.g., "I have often been late to work or classes in school"). In the YPI, respondents rate the degree to which the individual statements or items apply to them, 
using 4-point Likert-type scales $(1=$ does not apply at all; $2=$ does not apply well; $3=$ applies fairly well; $4=$ applies very well). To minimize the influence of social desirability on responses, the YPI frames psychopathic traits as neutral or pleasing. In the Pathways study, the YPI was administered at every follow-up interview. The correlations of the domains were found to be strong (range, $r=0.59-0.67$, $\mathrm{p}<0.001$ ), and the internal consistency for the YPI total score and the domain scores was adequate (range, $\alpha=0.73-0.94)$.

\section{Offending}

The Self-Report of Offending scale (SRO; Huizinga et al., 1991) was coded dichotomously $(0=$ no acts; $1=$ at least one act) by creating a dummy variable to indicate any or no antisocial and illegal acts in the recall period of 6 or 12 months. The original measure in the Pathways to Desistance study consists of 24 items which indicate adolescent's involvement in income offending (e.g., "Used checks or credit cards illegally?") and aggressive crimes (e.g., "Been in a fight?").

\section{Parental warmth and hostility}

The parental warmth and hostility measure were based on the Quality of Parental Inventory (Conger et al., 1994). It assesses the affective tone of the parentadolescent relationship via adolescent self-report. Items from the measure tap both maternal and paternal warmth (e.g., "How often does your mother/father let you know she/he really cares about you?") and hostility (e.g., "How often does your mother/father get angry at you?"). The scale contains 42 items in total, and participants are asked to provide answers to every item on a 4-point Likert scale $(1=$ Always, $2=$ Often, $3=$ Sometimes, 4 $=$ Never). The parental warmth scale is calculated from the mean of 9 items, and the hostility scale from the mean of 12 items, separately for both mothers and fathers. Items were reverse coded to generate the composite scores, with higher scores indicating a more supportive and nurturing parental relationship on the warmth scale and higher scores on the hostility scale indicating a more hostile relationship. The subscales for mother, farther, warmth and hostility were used separately. The parent of focus in this measure was not limited to the biological mother and father; the primary caregiver could be any adult responsible for raising the adolescent. The measure was skipped if the adolescent was at the age of 20 or older meaning that the last two (ninth and tenth follow-up interviews) were totally excluded from this study. The internal consistency for the parental subscales were high (range, $\alpha=0.80-0.95$ ).

\section{Parental figures}

If the adolescent spent the majority of the recall period in a community location (i.e., their own place, a private home, from place to place, on the streets, or other specified), the questions pertained to parental figures in the specified location. Specifically, adolescents responded "yes" or "no" to the questions regarding biological, step, and adoptive mother and father living in the location. A dichotomous question regarding contact with a primary caregiver was alternatively asked if the adolescent spent the majority of the recall period in an institution (i.e., jail or detention). The adolescent was asked to respond "yes" or "no" regarding whether they were in contact with their primary female/male caregiver in the recall period. Covariates of maternal and paternal figures were formed by categorizing the answers into five different categories in terms of the principal living conditions of the recall period (e.g., for mothers: $1=$ participant in community and biological mother living in the location, $2=$ participant in community and step/adoptive mother living in the location, $3=$ participant in community and no maternal figure living in the location, $4=$ participant in institution and in contact with mother, $5=$ participant in institution and no contact with mother). There was an assumption that this figure was the primary caregiver on whom the adolescent reported in the parental warmth and hostility section. The parental figure covariate indicates whether the adolescent was in contact with the figure across the recall period.

\section{Time-variant and -invariant variables}

The study wave, gender, ethnicity and age of the adolescent were added into the analyses as control variables. The study waves were the eight follow-ups of $6,12,18,24,30,36,48$ and 60 months, and age varied from 14 to 19 between respondents. In terms of time-invariant covariates, gender and ethnicity were constant through the whole study.

\section{Statistical Analysis}

Repeated measurements of parental behaviors and psychopathic traits were collected from 8 study waves of 1354 participants, resulting in 7135 person-observations (i.e., an average of 5.3 person-observations per participant). Adolescents 20 years or older were omitted from the data used in this study because the parental warmth and hostility measure was filled in only if the participant was under the age of 20 at the time of the follow-up interview.

We used multilevel longitudinal data analysis in which the repeated measurements (level 1) were nested within individuals (level 2). The overall coefficients of these multilevel models represented the combination of (1) 
Table 1 Descriptive statistics for the person-observations from 1354 individuals over the 8 data collection waves in the Pathways to Desistance study, 2000-2010

\begin{tabular}{lccc}
\hline Variable $^{\mathrm{a}}$ & Total $N$ & Mean (SD)/\% & Range \\
\hline Age & 7135 & $17.56(0.01)$ & $14-19$ \\
Gender & & & \\
$\quad$ Male & 6124 & $85.83 \%$ & \\
$\quad$ Female & 1011 & $14.17 \%$ & \\
Ethnicity & & & \\
$\quad$ White & 1530 & $21.44 \%$ & \\
$\quad$ Black & 2861 & $40.10 \%$ & \\
$\quad$ Hispanic & 2427 & $34.02 \%$ & \\
$\quad$ Other & 317 & $4.44 \%$ & \\
SRO & & & \\
$\quad$ No offences & 3742 & $52.52 \%$ & \\
One or more offences & 3383 & $47.48 \%$ & \\
Maternal warmth & & $3.12(0.01)$ & $1-4$ \\
Maternal hostility & & $1.42(0.01)$ & $1-4$ \\
Paternal warmth & & $2.74(0.02)$ & $1-4$ \\
Paternal hostility & & $1.32(0.01)$ & $1-4$ \\
YPI & & $104.87(0.28)$ & $50-197$ \\
& &
\end{tabular}

Spent majority of the recall period:

\begin{tabular}{|c|c|c|}
\hline In community ${ }^{\mathrm{b}}$ & 4606 & $64.56 \%$ \\
\hline $\begin{array}{l}\text { Biological mother living in } \\
\text { the community location }\end{array}$ & & $62.24 \%$ \\
\hline Step mother & & $2.84 \%$ \\
\hline Adoptive mother & & $0.74 \%$ \\
\hline Biological father & & $21.24 \%$ \\
\hline Step father & & $12.45 \%$ \\
\hline Adoptive father & & $0.59 \%$ \\
\hline In institution & 2529 & $35.44 \%$ \\
\hline $\begin{array}{l}\text { Had any contact with } \\
\text { primary female caregiver in } \\
\text { the recall period }\end{array}$ & & $97.65 \%$ \\
\hline $\begin{array}{l}\text { Had any contact with } \\
\text { primary male caregiver in } \\
\text { the recall period }\end{array}$ & & $84.69 \%$ \\
\hline
\end{tabular}

Percentages and numbers calculated based on person-observations. Total $n=7135$ person-observations of 1354 persons

$S D$ standard deviation, SRO self-reported offending, YPI Youth Psychopathic Traits Inventory total score

${ }^{\text {a }}$ For categorical variables, the values are the number of total personobservations and percentages calculated from person-observations. For continuous variables, the values are means, overall standard deviations, and within-individual standard deviations

${ }^{\mathrm{b}}$ Own place, private home (different options), from place to place, different people, on streets/homeless

average differences between different individuals and (2) within-individual differences across the measurement times. By estimating only the within-individual changes-also known as fixed-effects models-it is possible to improve causal inference because this analysis is not confounded by stable individual differences that do not change over time, because the analysis only takes into account withinindividual variation (see Curran \& Bauer, 2011). The equation for the fixed-effects model can be expressed as a linear function of time: $y t i=\beta 0 i+\beta 1$ ixti $+\mathrm{rti}$, where $\beta 0 \mathrm{i}$ is the intercept, $\beta 1 \mathrm{i}$ is the linear slope for the ith individual, $x t i$ is the observed value of time at a follow-up time $t$ for individual $\mathrm{i}$, and $\mathrm{rti}$ is the time- and individual-specific residual.

Adolescent self-reported maternal warmth and hostility of the past recall period were the main time-varying independent variables, and self-reported YPI score was the dependent variable (Model 1). Interaction terms of maternal warmth and hostility with the age of the adolescent were then added into the analyses, with age centered at its mean value. Time-invariant covariates included gender and ethnicity, and time-varying covariates included the contact with parental figures, age of the subject, self-reported offending, and study wave. Similar analyses were performed with adolescent self-reported paternal warmth and hostility (Model 2). In order to test parental behaviors on self-reported offending, logistic regressions were calculated to predict self-reported offending based on parental warmth and hostility, further adjusted for psychopathic traits (Models 3 and 4). In addition, the temporal associations were further tested with YPI as the independent variable and forward-lagged parental warmth and hostility as the dependent variables, so that YPI assessed at wave $n$ predicted parental warmth and hostility at wave $n+l$ (Model 5). Data analyses were conducted using the xtreg and xtlog commands of Stata, version 15.1 (Stata Corp. LP, College Station, Texas, USA) statistical software.

\section{Results}

Descriptive statistics showed that over $64 \%$ of the personobservations were collected when the participant had spent the majority of the recall period in the community (Table 1). Of those observations, $62.2 \%$ reported that their biological mother lived in the same location, while $21.2 \%$ reported the same about their biological father. The proportions were smaller for step and adoptive parents $(0.59-12.45 \%)$. Thirty five percent of the person-observations were reported as being spent in an institution during the recall period, and the majority had some contact with their primary female caregiver $(97.7 \%)$ as well as with their primary male caregiver $(84.7 \%)$. More than half of the all person-observations $(52.5 \%)$ in this study did not include committing a crime during the recall period. The YPI total score ranged between 50 and 197 , with a mean score of $104.87(\mathrm{SD}=0.28)$ reflecting a rather high average level of psychopathic symptoms compared to general population. Males scored 
Table 2 Regression coefficients of independent variables and covariates for psychopathy (YPI)

\begin{tabular}{|c|c|c|c|c|}
\hline & \multicolumn{2}{|l|}{ Model 1} & \multicolumn{2}{|l|}{ Model 2} \\
\hline & $\begin{array}{l}\text { Random-effects } \\
\text { GLS regression }\end{array}$ & $\begin{array}{l}\text { Fixed-effects } \\
\text { (within) } \\
\text { regression }\end{array}$ & $\begin{array}{l}\text { Random-effects } \\
\text { GLS regression }\end{array}$ & $\begin{array}{l}\text { Fixed-effects } \\
\text { (within) regression }\end{array}$ \\
\hline & $\beta(\mathrm{SE})$ & $\beta(\mathrm{SE})$ & $\beta(\mathrm{SE})$ & $\beta(\mathrm{SE})$ \\
\hline \multicolumn{5}{|c|}{ Self-report measure of mothers } \\
\hline Maternal warmth & $-3.95 *(0.45)$ & $-3.61 *(0.52)$ & & \\
\hline Maternal hostility & $6.60 *(0.81)$ & $5.13 *(0.90)$ & & \\
\hline Age & $0.66(1.48)$ & $0.66(1.66)$ & & \\
\hline $\begin{array}{l}\text { Maternal warmth } \times \\
\text { age }\end{array}$ & $-0.24(0.32)$ & $-0.30(0.34)$ & & \\
\hline $\begin{array}{l}\text { Maternal hostility } \times \\
\text { age }\end{array}$ & $-0.14(0.58)$ & $-0.15(0.60)$ & & \\
\hline \multicolumn{5}{|c|}{ Self-report measure of fathers } \\
\hline Paternal warmth & & & $-3.26^{*}(0.52)$ & $-2.76^{*}(0.63)$ \\
\hline Paternal hostility & & & $5.05^{*}(1.16)$ & $3.48 * *(1.31)$ \\
\hline Age & & & $-2.21(1.78)$ & $-4.30 * * *(2.10)$ \\
\hline $\begin{array}{l}\text { Paternal warmth } \times \\
\text { age }\end{array}$ & & & $-0.02(0.37)$ & $0.05(0.40)$ \\
\hline $\begin{array}{l}\text { Paternal hostility } \times \\
\text { age }\end{array}$ & & & $1.24(0.85)$ & $1.07(0.91)$ \\
\hline \multicolumn{5}{|l|}{ Covariates } \\
\hline Mother/father & $0.44 * * *(0.21)$ & $0.37(0.23)$ & $0.42(0.34)$ & $0.28(0.37)$ \\
\hline SRO & $5.66 *(0.60)$ & $2.98 *(0.65)$ & $5.41 *(0.81)$ & $2.21 * * *(0.89)$ \\
\hline Study wave & $-0.84 * *(0.26)$ & $-0.77(0.47)$ & $-0.70 * * *(0.34)$ & $0.58(0.62)$ \\
\hline Gender & $-8.16^{*}(1.44)$ & & $-7.52 *(1.94)$ & \\
\hline Ethnicity & $-1.06(0.63)$ & & $-1.21(0.80)$ & \\
\hline
\end{tabular}

$S E$ standard error, SRO self-reported offending, YPI Youth Psychopathic Traits Inventory total score, Mother/father contact with the parental figure during the recall period

$* p<0.001 ; * * p<0.01 ; * * * p<0.05$ higher than females on the YPI total score. Regarding parental factors, the mean score was $3.12(S D=0.01$; range $1-4)$ for maternal warmth and $2.74(S D=0.02$; range $1-4)$ for paternal warmth, with higher scores demonstrating more supportive and nurturing parental relationships. In contrast, the mean scores for parental hostility were $1.42(S D=0.01)$ for mothers and $1.32(S D=0.01)$ for fathers with ranges of 1-4, with higher ratings reflecting a more hostile relationship.

The results of the linear multilevel analyses (Model 1 and 2 ) are presented in Table 2. Both maternal and paternal warmth had main effects on psychopathic traits $(p<0.001)$ in random-effects and fixed-effects models after controlling for the contact with parental figures, age of the subject, selfreported offending, study wave and time-invariant factors. The effect was negative, indicating that the more supportive and nurturing the parent, the smaller the scores in the YPI. Also, parental hostility variables showed significant associations with self-reported psychopathic traits in both fixedand random-effects models $(p<0.01)$. Contrarily, the effect was positive between parental hostility and psychopathic traits, reflecting higher scores in the YPI if the adolescent rated the parent as more hostile. In terms of interactions, the age of the adolescent did not moderate the associations, and age did not have a main effect on psychopathic traits either. Maternal warmth was associated with lower, and both maternal and paternal hostility were associated with higher odds of having committed crimes during the recall period (Model 3 and 4). When further adjusted for psychopathic traits, the significance of these associations remained the same (Table 3). The association of paternal warmth was not observed in the fixed-effect regression. Table 4 shows that the time-lagged associations of psychopathic traits predicting parental warmth and hostility in the next follow-up wave were not observed in fixed-effects models (Model 5).

\section{Discussion}

Our novel findings show that certain contextual factors, such as parenting, may be related to psychopathic traits and the likelihood to committing crimes in adolescence and 
Table 3 Linear regression coefficients between parental behaviors and self-reported offending for within-individual analyses across 8 follow-ups

\begin{tabular}{|c|c|c|c|c|c|c|}
\hline & \multicolumn{3}{|l|}{ SRO } & \multicolumn{3}{|c|}{ SRO after controlling for YPI } \\
\hline & $\beta$ & $95 \% \mathrm{CI}$ & & $\beta$ & $95 \% \mathrm{CI}$ & \\
\hline \multicolumn{7}{|l|}{ Model 3} \\
\hline Maternal warmth & $-0.32 *$ & -0.49 & -0.15 & $-0.31 *$ & -0.49 & -0.13 \\
\hline Maternal hostility & $0.50 * *$ & 0.20 & 0.79 & $0.45 * *$ & 0.14 & 0.75 \\
\hline Age & $0.31 * * *$ & 0.04 & 0.57 & $0.28 * * *$ & 0.01 & 0.55 \\
\hline Mother & -0.04 & -0.11 & 0.04 & -0.05 & -0.12 & 0.03 \\
\hline Study wave & $-0.31 *$ & -0.47 & -0.16 & -0.29 & -0.44 & -0.13 \\
\hline YPI & & & & $1.23 *$ & 0.65 & 1.81 \\
\hline \multicolumn{7}{|l|}{ Model 4} \\
\hline Paternal warmth & -0.10 & -0.31 & 0.11 & -0.10 & -0.32 & 0.11 \\
\hline Paternal hostility & $1.02 *$ & 0.56 & 1.49 & $0.98 *$ & 0.50 & 1.46 \\
\hline Age & 0.24 & -0.15 & 0.62 & 0.19 & -0.21 & 0.58 \\
\hline Father & 0.03 & -0.10 & 0.16 & 0.04 & -0.09 & 0.17 \\
\hline Study wave & $-0.29 * *$ & -0.51 & -0.07 & -0.25 & -0.48 & -0.03 \\
\hline YPI & & & & $1.00 * * *$ & 0.09 & 1.91 \\
\hline
\end{tabular}

Analyses were first adjusted for the age of the respondent, contact with the parental figure during the recall period, and study wave, and then for psychopathic traits. Values are B-coefficients (and 95\% confidence intervals) of logistic regression for self-reported offending

$S R O$ self-reported offending, YPI Youth Psychopathic Traits Inventory total score

$* p<0.001 ; * * p<0.01 ; * * * p 0.05$ young adulthood. This study aimed to test whether adolescent self-reported parental warmth and hostility predict changes in self-reported psychopathic traits and selfreported offending in a high-risk sample of delinquent adolescents of 14 to 19 years old. The current study extends the prior literature of the associations between parental practices and psychopathic behavior conducted with adult (Gao et al., 2010), adolescent (Bisby et al., 2017; Chinchilla \& Kosson, 2016; Ray, 2018), and child samples (Barker et al., 2011; Larsson et al., 2008; Pardini et al., 2007; Waller et al., 2015). Our study is in line with an earlier study with the Pathways to Desistance study (Ray, 2018), except that our within-individual analysis did suggest a temporal and potentially causal association between parenting and development of psychopathic behaviors whereas the previous study mainly suggested an association with baseline psychopathic traits but no time-varying association. Our within-individual analysis differs from the earlier timevarying analysis of Ray (2018) in that the within-individual analysis adjusts for the average levels between individuals. Our analysis also examined maternal and paternal measures separately, we included parental warmth and hostility as indicators of parenting, and we controlled for the contact with the caregiver and self-reported offending.

Consistent with hypotheses, maternal warmth-indicating supportive and nurturing relationship-associated negatively with psychopathic traits and offending. Paternal warmth protected from psychopathic traits but not from delinquency. In contrast, maternal and paternal hostility- parent's hostility, angry coerciveness, and antisocial behavior toward the adolescent-linked positively to these traits and acts. The associations were observed within the same individuals followed over time with eight repeated assessments, suggesting a causal association between parental practices and psychopathic traits and offending. Our results support studies indicating that parental behaviors may shape psychopathic behavior of a young criminal population, and notably, the effect is not restricted to childhood, but parental warmth and hostility matter also in adolescence (Bisby et al., 2017; Chinchilla \& Kosson, 2016; Kimonis et al., 2013). Moreover, according to our findings, the age of the respondent did not moderate the relationship between parental behaviors and psychopathic traits suggesting that parental warmth and hostility may shape the levels of selfreported psychopathic traits at the age 14 and 19 similarly. The data emphasize thus the continued importance of parental behaviors during adolescence despite demands for autonomy and independence (Buck, 2015; Hill et al., 2007). This study expands the literature by showing that the effects of parenting are not restricted to early and middle childhood but matter at later developmental stages (Buck, 2015; Gardner et al., 2019). Both early and later warmth seem to be important in lowering self-reported psychopathic traits of adolescents.

Our study suggests that parental practices are not a reaction to psychopathic traits in adolescence, because the reverse relationship of psychopathic traits predicting later parental warmth and hostility was not supported in this 


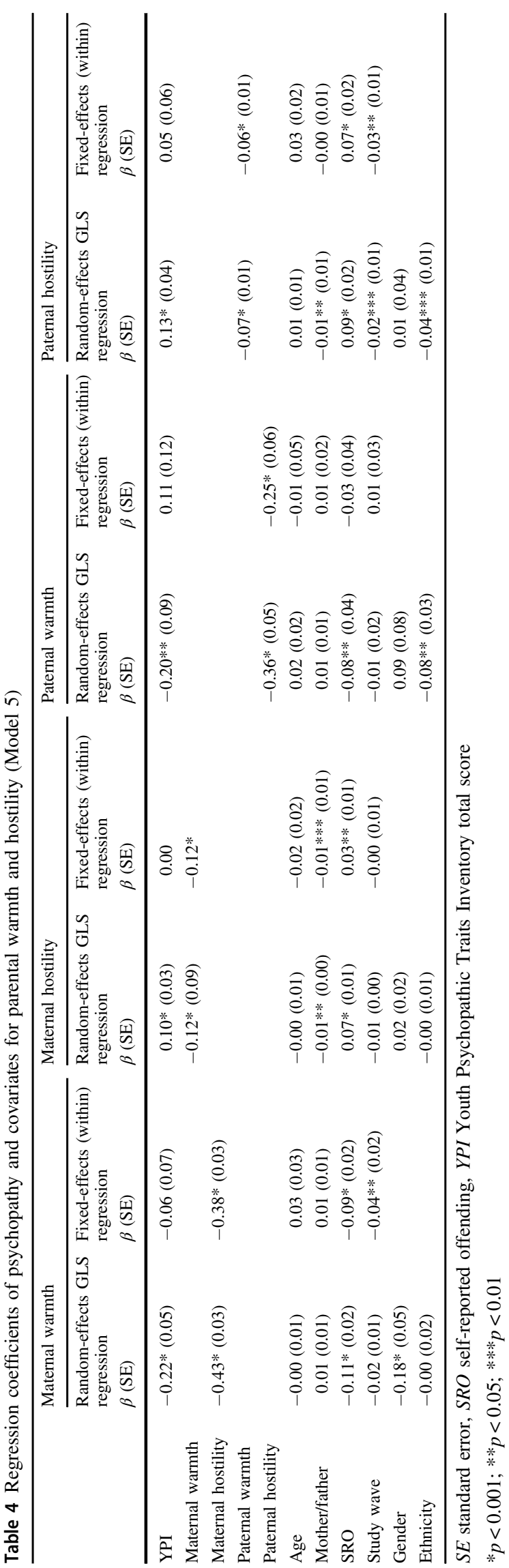

study at an individual level. Although an association was discovered in the random-effect analysis, it likely results from various confounding background factors rather than from causal effects over time. Accordingly, this finding did not support previous findings of bidirectional effects between parenting characteristics and psychopathic traits (Hawes et al., 2011; Larsson et al., 2008; Muñoz et al., 2011; Salihovic et al., 2012). Both Hawes et al. (2011) and Larsson et al. (2008) studied child samples and focused on parenting practices such as harsh and inconsistent discipline, instead of warmth or hostility. Also, the focus was on parental knowledge and monitoring in the study of Muñoz et al. (2011). On the contrary, Salihovic et al. (2012) studied adolescents annually for 4 years, and they measured parental warmth with 6 statements and parental coldness/rejection and angry outbursts with 11 statements. However, the most evident difference between their and our study may be methodological. We studied the variation via a withinindividual effect, which is a measure of how much the adolescent tends to change over time, whereas they concentrated on a model comparison approach.

The mechanisms and processes that underpin parental behaviors and psychopathic traits remain unclear. Although our study indicates that adolescent self-reported, i.e. subjectively experienced, parental warmth may lower their self-reported psychopathic traits and offending, and subjectively experienced parental hostility may strengthen the traits and acts, it is unable to address whether parental warmth elicits changes in adolescent's sensitivity to others, emotional responsivity, empathy or the ability to prioritize the feelings of others, for example. Based on previous literature, parental warmth may improve adolescents' social (Pasalich et al., 2016) and emotion processing skills (Lui et al., 2019), or warm parenting style may motivate youth to find it rewarding to affiliate and attach with others (Kimonis et al., 2019; Viding \& McCrory, 2019), which in turn makes levels of psychopathic traits of children and adolescents amenable to change. These findings have been found in studies of parental based intervention that directly aim to reduce psychopathic behavior in adolescents (see Hawes et al., 2014; Wilkinson et al., 2016 for reviews). Although children with conduct problems and high levels of $\mathrm{CU}$ traits respond more poorly to parent training and familybased interventions than children with conduct problems and low levels of CU traits (Hawes et al., 2014; Waller et al., 2013), few studies have found positive effects through parent training in reducing $\mathrm{CU}$ traits per se in children (Blader et al., 2013; Kimonis et al., 2019; Kolko et al., 2009; Lochman et al., 2014), and in adolescents (Lui et al., 2019; Pasalich et al., 2016; Salekin et al., 2012). More research is needed to uncover how differences in 
experiences of parental behaviors relate to environmental factors and change in psychopathic traits.

The many strengths of the present study, such as multilevel longitudinal data analysis with a large sample size of high-risk adolescents, a longitudinal design with 8 assessments over 4.5 years, and a broad scope of parental behaviors with both parental warmth and hostility, are also linked to four main limitations. In particular, the generalizability of the findings may be limited by the use of offending adolescents. International studies outside criminal settings with both children and adolescent samples are warranted. Second, relying on a single source of measurement, adolescents' self-reports of their own and their parents' behavior, is another limitation. It introduces a possibility of shared method variance; however, forensic settings and the age of the respondent may limit exposure to reliable parent reports. In future studies the validity of the constructs should be enhanced by using parent report of parental behaviors. In addition, questions of heritability and possible gene-environment correlation are beyond the study due to the nature of self-reported data. Third, only parental warmth and hostility, not parental monitoring were measured in the study. There has been discussion regarding whether youth with psychopathic traits tend to take advantage of permissive parenting styles displaying warmth without structure (Ray et al., 2017). Importantly, it is possible that other effects of parenting youth under 14 year old exist since the process of the parent-child relationship is dynamic and thus varies as the youth matures. Finally, we did not control for the frequency of the contact with the parental figure. In terms of a possible exposure, it may not be the same to have a consistent, daily or near-daily warmth or hostility from a caregiver than an occasional warm or hostile contact with the figure. This should be considered a possible covariate of importance in future studies.

The current results suggest that parenting quality matters and may lower the risk of psychopathy and further delinquency in adolescence and young adulthood. Research on psychopathic traits and juvenile delinquency has a significant health gain for the society given the public burden of this minority of forensic adolescents. Interventions that target the promotion of warm and supportive parent-child relationships, and the reduction of a parental hostility and angry coerciveness may prove helpful for forensic adolescents with psychopathic traits. In terms of rehabilitation and treatment, parenting could be addressed not only on the secondary prevention level, i.e., with adolescents who are at risk or show early signs of antisociality, but also with adolescents showing serious antisocial conduct. In future studies, parental monitoring and the amount of exposure of parental warmth and hostility should be taken into account.

\section{Conclusion}

There is a growing evidence that particular environmental factors such as parental behaviors may contribute the levels of youth psychopathic traits, both behavioral expressions and affective features called CU traits (Hawes et al., 2014; Pardini et al., 2007; Waller et al., 2013). Positive parenting such as warmth is suggested to prevent from psychopathic-like behavior in childhood (Hawes et al., 2011; Pardini et al., 2007), while the outcomes of childhood negative parenting may be detected even in adolescence and young adulthood through psychopathic behavior (Goulter et al., 2020; Waller et al., 2015). Parental warmth and hostility during adolescence are less studied, although effects of parenting are suggested to be equally strong in different developmental stages in early, middle and late childhood (Gardner et al., 2019), and parental behaviors associate with the levels of psychopathic traits also in adolescence (Buck, 2015; Bisby et al., 2017). However, there is a lack of knowledge, how coexistent maternal and paternal warmth and hostility affect the levels of psychopathic traits-including interpersonal, behavioral and affective domains-over time of adolescents who are already on an offending path. This study indicates that parental warmth through adolescent self-report may protect against the psychopathic traits and criminal acts of delinquent adolescents at age 14 to 19 , whereas maternal and paternal hostility can strengthen the traits and antisocial outcomes. The effect of parenting quality and psychopathic traits was not moderated by the age of the adolescent, and youth psychopathic traits failed to explain parental warmth and hostility. In conclusion, parenting quality matters in adolescence, such that parental behaviors may act either as protective or risk factors on psychopathic traits and delinquency in adolescence depending on the warmth and hostility of the relationship at this developmental period. Further longitudinal studies should identify the underlying mechanisms of parental warmth that reduce the likelihood of psychopathic behavior in adolescence. In the future, it is also important to understand the interaction between environmental factors and temperamental, neurocognitive and genetic variables involved in psychopathic traits.

Funding Open access funding provided by University of Helsinki including Helsinki University Central Hospital.

\section{Compliance with Ethical Standards}

Conflict of Interest The authors declare no conflict of interest.

Publisher's note Springer Nature remains neutral with regard to jurisdictional claims in published maps and institutional affiliations. 
Open Access This article is licensed under a Creative Commons Attribution 4.0 International License, which permits use, sharing, adaptation, distribution and reproduction in any medium or format, as long as you give appropriate credit to the original author(s) and the source, provide a link to the Creative Commons license, and indicate if changes were made. The images or other third party material in this article are included in the article's Creative Commons license, unless indicated otherwise in a credit line to the material. If material is not included in the article's Creative Commons license and your intended use is not permitted by statutory regulation or exceeds the permitted use, you will need to obtain permission directly from the copyright holder. To view a copy of this license, visit http://creativecommons. org/licenses/by/4.0/.

\section{References}

Andershed, H. A., Kerr, M., Stattin, H., \& Levander, S. (2002). Psychopathic traits in non-referred youths: a new assessment tool. In E. Blaauw, \& L. Sheridan (Eds.), Psychopaths: current international perspectives (pp. 131-158). Elsevier.

Barker, E. D., Oliver, B. R., Viding, E., Salekin, R. T., \& Maughan, B. (2011). The impact of prenatal maternal risk, fearless temperament and early parenting on adolescent callous-unemotional traits: a 14-year longitudinal investigation. Journal of Child Psychology and Psychiatry, 52(8), 878-888.

Bergstrøm, H., \& Farrington, D. P. (2018). Grandiose-manipulative, callous-unemotional, and daring-impulsive: the prediction of psychopathic traits in adolescence and their outcomes in adulthood. Journal of Psychopathology and Behavioral Assessment, 40(2), 149-158.

Bisby, M. A., Kimonis, E. R., \& Goulter, N. (2017). Low maternal warmth mediates the relationship between emotional neglect and callous-unemotional traits among male juvenile offenders. Journal of Child and Family Studies, 26(7), 1790-1798.

Blader, J. C., Pliszka, S. R., Kafantaris, V., Foley, C. A., Crowell, J. A., Carlson, G. A., \& Daviss, W. B. (2013). Callousunemotional traits, proactive aggression, and treatment outcomes of aggressive children with attention-deficit/hyperactivity disorder. Journal of the American Academy of Child \& Adolescent Psychiatry, 52, 1281-1293.

Blair, R. J. R. (2013). The neurobiology of psychopathic traits in youths. Nature Reviews Neuroscience, 14(11), 786.

Buck, K. A. (2015). Understanding adolescent psychopathic traits from early risk and protective factors: Relations among inhibitory control, maternal sensitivity, and attachment representation. Journal of Adolescence, 44, 97-105.

Byrd, A. L., Loeber, R., \& Pardini, D. A. (2014). Antisocial behavior, psychopathic features and abnormalities in reward and punishment processing in youth. Clinical Child and Family Psychology Review, 17(2), 125-156.

Chinchilla, M. A., \& Kosson, D. S. (2016). Psychopathic traits moderate relationships between parental warmth and adolescent antisocial and other high-risk behaviors. Criminal Justice and Behavior, 43(6), 722-738.

Conger, R. D., Ge, X., Elder, Jr, G. H., Lorenz, F. O., \& Simons, R. L. (1994). Economic stress, coercive family process, and developmental problems of adolescents. Child Development, 65 (2), 541-561.

Curran, P. J., \& Bauer, D. J. (2011). The disaggregation of withinperson and between-person effects in longitudinal models of change. Annual Review of Psychology, 62, 583-619.

Dawel, A., O'kearney, R., McKone, E., \& Palermo, R. (2012). Not just fear and sadness: meta-analytic evidence of pervasive emotion recognition deficits for facial and vocal expressions in psychopathy. Neuroscience \& Biobehavioral Reviews, 36(10), 2288-2304.

Flom, M., White, D., Ganiban, J., \& Saudino, K. J. (2020). Longitudinal links between callous-unemotional behaviors and parenting in early childhood: a genetically informed design. Journal of the American Academy of Child \& Adolescent Psychiatry, 59 (3), 401-409.

Forth, A. E., Kosson, D. S., \& Hare, R. D. (2003). Hare psychopathy checklist: youth version. Multi-Health Systems.

Frick, P. J., Kimonis, E. R., Dandreaux, D. M., \& Farell, J. M. (2003). The 4 year stability of psychopathic traits in non-referred youth. Behavioral Sciences \& the Law, 21(6), 713-736.

Frick, P. J., Ray, J. V., Thornton, L. C., \& Kahn, R. E. (2014). Annual research review: a developmental psychopathology approach to understanding callous-unemotional traits in children and adolescents with serious conduct problems. Journal of Child Psychology and Psychiatry, 55(6), 532-548.

Frick, P. J., \& White, S. F. (2008). Research review: the importance of callous-unemotional traits for developmental models of aggressive and antisocial behavior. Journal of Child Psychology and Psychiatry, 49(4), 359-375.

Gao, Y., Raine, A., Chan, F., Venables, P. H., \& Mednick, S. A. (2010). Early maternal and paternal bonding, childhood physical abuse and adult psychopathic personality. Psychological Medicine, 40(6), 1007-1016.

Gardner, F., Leijten, P., Melendez-Torres, G. J., Landau, S., Harris, V., Mann, J., \& Scott, S. (2019). The earlier the better? Individual participant data and traditional meta-analysis of age effects of parenting interventions. Child Development, 90(1), 7-19.

Goulter, N., McMahon, R. J., Pasalich, D. S. \& Dodge, K. A. (2020). Indirect effects of early parenting on adult antisocial outcomes via adolescent conduct disorder symptoms and callous-unemotional traits. Journal of Clinical Child \& Adolescent Psychology, 49(6), 930-942.

Hare, R. D., \& Neumann, C. S. (2008). Psychopathy as a clinical and empirical construct. Annu. Rev. Clin. Psychol., 4, 217-246.

Hawes, D. J., Dadds, M. R., Frost, A. D., \& Hasking, P. A. (2011). Do childhood callous-unemotional traits drive change in parenting practices? Journal of Clinical Child \& Adolescent Psychology, 40 (4), 507-518.

Hawes, D. J., Price, M. J., \& Dadds, M. R. (2014). Callousunemotional traits and the treatment of conduct problems in childhood and adolescence: A comprehensive review. Clinical Child and Family Psychology Review, 17(3), 248-267.

Henry, J., Dionne, G., Viding, E., Petitclerc, A., Feng, B., Vitaro, F., \& Boivin, M. (2018). A longitudinal study of callousunemotional traits during childhood. Journal of Abnormal Psychology, 127(4), 374.

Hill, N. E., Bromell, L., Tyson, D. F., \& Flint, R. (2007). Developmental commentary: ecological perspectives on parental influences during adolescence. Journal of Clinical Child and Adolescent Psychology, 36(3), 367-377.

Huizinga, D., Esbensen, F., \& Weihar, A. (1991). Are there multiple paths to delinquency? Journal of Criminal Law and Criminology, $82,83-118$

Hyde, L. W., Waller, R., Trentacosta, C. J., Shaw, D. S., Neiderhiser, J. M., Ganiban, J. M., \& Leve, L. D. (2016). Heritable and nonheritable pathways to early callous-unemotional behaviors. American Journal of Psychiatry, 173(9), 903-910.

Jokela, M., Airaksinen, J., Kivimäki, M., \& Hakulinen, C. (2018). Is within-individual variation in personality traits associated with changes in health behaviours? Analysis of seven longitudinal cohort studies. European Journal of Personality, 32(6), 642-652.

Kimonis, E. R., Cross, B., Howard, A., \& Donoghue, K. (2013). Maternal care, maltreatment and callous-unemotional traits 
among urban male juvenile offenders. Journal of Youth and Adolescence, 42(2), 165-177.

Kimonis, E. R., Fleming, G., Briggs, N., Brouwer-French, L., Frick, P. J., Hawes, D. J., \& Dadds, M. (2019). Parent-child interaction therapy adapted for preschoolers with callous-unemotional traits: an open trial pilot study. Journal of Clinical Child \& Adolescent Psychology, 48(sup1), S347-S361.

Kochanska, G. (1997). Mutually responsive orientation between mothers and their young children: implications for early socialization. Child Development, 68(1), 94-112.

Kolko, D. J., Dorn, L. D., Bukstein, O. G., Pardini, D., Holden, E. A., \& Hart, J. (2009). Community vs. clinic-based modular treatment of children with early-onset ODD or CD: a clinical trial with 3-year follow-up. Journal of Abnormal Child Psychology, 37, 591-609.

Larsson, H., Viding, E., \& Plomin, R. (2008). Callous-unemotional traits and antisocial behavior: genetic, environmental, and early parenting characteristics. Criminal Justice and Behavior, 35(2), 197-211.

Lochman, J. E., Baden, R. E., Boxmeyer, C. L., Powell, N. P., Qu, L., Salekin, K. L., \& Windle, M. (2014). Does a booster session augment the preventive effects of an abbreviated version of the Coping Power Program for aggressive children? Journal of Abnormal Child Psychology, 42, 367-381.

Lui, J. H., Barry, C. T., \& Marcus, D. K. (2019). A short-term intervention for adolescents with callous-unemotional traits and emotion-processing deficits. Journal of Social and Clinical Psychology, 38(6), 475-500.

Lynam, D. R., Charnigo, R., Moffitt, T. E., Raine, A., Loeber, R., \& Stouthamer-Loeber, M. (2009). The stability of psychopathy across adolescence. Development and Psychopathology, 21(4), $1133-1153$.

Lynam, D. R., Loeber, R., \& Stouthamer-Loeber, M. (2008). The stability of psychopathy from adolescence into adulthood: the search for moderators. Criminal Justice and Behavior, 35(2), 228-243.

Marsh, A. A., \& Blair, R. J. R. (2008). Deficits in facial affect recognition among antisocial populations: a meta-analysis. Neuroscience \& Biobehavioral Reviews, 32(3), 454-465.

Moore, A. A., Blair, R. J., Hettema, J. M. \& Roberson-Nay, R. (2019). The genetic underpinnings of callous-unemotional traits: A systematic research review. Neuroscience \& Biobehavioral Reviews, 100, 85-97.

Muñoz, L., Pakalniskiene, V., \& Frick, P. J. (2011). Parental monitoring and youth problem behaviors: moderation by callousunemotional traits over time. European Child \& Adolescent Psychiatry, 20(5), 261-269. https://doi.org/10.1007/s00787-011-0172-6.

Pardini, D. A., Lochman, J. E., \& Powell, N. (2007). The development of callous-unemotional traits and antisocial behavior in children: are there shared and/or unique predictors? Journal of Clinical Child and Adolescent Psychology, 36(3), 319-333.

Pasalich, D. S., Dadds, M. R., Hawes, D. J., \& Brennan, J. (2011). Do callous-unemotional traits moderate the relative importance of parental coercion versus warmth in child conduct problems? An observational study. Journal of Child Psychology and Psychiatry, 52(12), 1308-1315.

Pasalich, D. S., Witkiewitz, K., McMahon, R. J., \& Pinderhughes, E. E., Conduct Problems Prevention Research Group. (2016). Indirect effects of the Fast Track intervention on conduct disorder symptoms and callous-unemotional traits: Distinct pathways involving discipline and warmth. Journal of Abnormal Child Psychology, 44(3), 587-597.

Ray, J. V. (2018). Developmental patterns of psychopathic personality traits and the influence of social factors among a sample of serious juvenile offenders. Journal of Criminal Justice, 58, 67-77.

Ray, J. V., Frick, P. J., Thornton, L. C., Wall Myers, T. D., Steinberg, L., \& Cauffman, E. (2017). Callous-unemotional traits predict self-reported offending in adolescent boys: the mediating role of delinquent peers and the moderating role of parenting practices. Developmental Psychology, 53, 319-328. https://doi.org/10. 1037/dev0000210.

Reidy, D. E., Kearns, M. C., Degue, S., Lilienfeld, S. O., Massetti, G. \& Kiehl, K. A. (2015). Why psychopathy matters: Implications for public health and violence prevention. Aggression and Violent Behavior, 24, 214-225.

Salekin, R. T., Tippey, J. G., \& Allen, A. D. (2012). Treatment of conduct problem youth with interpersonal callous traits using mental models: measurement of risk and change. Behavioral Sciences \& the Law, 30(4), 470-486.

Salekin, R. T., Andershed, H., Batky, B. D., \& Bontemps, A. P. (2018). Are callous unemotional (CU) traits enough? Journal of Psychopathology and Behavioral Assessment, 40(1), 1-5.

Salihovic, S., Kerr, M., Özdemir, M., \& Pakalniskiene, V. (2012). Directions of effects between adolescent psychopathic traits and parental behavior. Journal of Abnormal Child Psychology, 40(6), 957-969.

Schubert, C. A., Mulvey, E. P., Steinberg, L., Cauffman, E., Losoya, S. H., Hecker, T., Chassin, L., \& Knight, G. P. (2004). Operational lessons from the pathways to desistance project. Youth Violence and Juvenile Justice, 2, 237-255.

Tuvblad, C., Bezdjian, S., Raine, A. \& Baker, L. A. (2013). Psychopathic personality and negative parent-to-child affect: A longitudinal cross-lag twin study. Journal of Criminal Justice, 41(5), 331-341.

Viding, E., Fontaine, N. M., \& McCrory, E. J. (2012). Antisocial behaviour in children with and without callous-unemotional traits. Journal of the Royal Society of Medicine, 105(5), 195-200.

Viding, E., Fontaine, N. M., Oliver, B. R., \& Plomin, R. (2009). Negative parental discipline, conduct problems and callous-unemotional traits: Monozygotic twin differences study. The British Journal of Psychiatry, 195(5), 414-419.

Viding, E., \& McCrory, E. (2019). Towards understanding atypical social affiliation in psychopathy. The Lancet Psychiatry, 6(5), 437-444.

Viding, E., \& McCrory, E. J. (2012). Genetic and neurocognitive contributions to the development of psychopathy. Development and Psychopathology, 24(3), 969-983.

Waller, R., Gardner, F., \& Hyde, L. W. (2013). What are the associations between parenting, callous-unemotional traits, and antisocial behavior in youth? A systematic review of evidence. Clinical Psychology Review, 33(4), 593-608.

Waller, R., Shaw, D. S., Forbes, E. E., \& Hyde, L. W. (2015). Understanding early contextual and parental risk factors for the development of limited prosocial emotions. Journal of Abnormal Child Psychology, 43(6), 1025-1039.

Wilkinson, S., Waller, R., \& Viding, E. (2016). Practitioner review: involving young people with callous unemotional traits in treatment-does it work? A systematic review. Journal of Child Psychology and Psychiatry, 57(5), 552-565. 